\title{
Depression and anxiety symptoms among people with rifampicin-resistant tuberculosis receiving in-patient care in the National Pulmonology Reference Institute in Romania
}

\author{
Alexandru Stoichita ${ }^{1}$, Andreea Dumitrescu ${ }^{1}$, Ana Ciobanu ${ }^{2}$, Cristian Oancea $^{3}$, Fildan Petronela ${ }^{4}$, \\ Radu Dabja ${ }^{5}$, Kostyantyn Dumchev ${ }^{6}$, Andrei Dadu ${ }^{2}$, Beatrice Mahler-Boca ${ }^{1}$, Kristina Akopyan ${ }^{7,8}$
}

\begin{abstract}
${ }^{1}$ National Institute of Pneumophtisiology "Marius Nasta", Bucharest, Romania; ${ }^{2}$ World Health Organization, Regional Office for Europe, Copenhagen, Denmark; ${ }^{3}$ University of Medicine and Pharmacy" Victor Babes",

Timisoara, Romania; "Faculty of Medicine "Ovidius", University of Constanta, Constanta, Romania; ${ }^{5}$ University of Medicine and Pharmacy "Prof. Dr. Grigore T. Popa", Iasi, Romania; ${ }^{6}$ Ukrainian Institute on Public Health, Kyiv, Ukraine; ${ }^{7}$ Tuberculosis Research and Prevention Center NGO, Yerevan, Armenia; ${ }^{8}$ National Center for Infectious Diseases, Yerevan, Armenia
\end{abstract}

Correspondence: Alexandru Stoichita, National Institute of Pneumonology "Marius Nasta", 90, Soseaua Viilor, Bucharest 050152, Romania.

Tel. +40.751151625 .

E-mail: dr.alexandru.stoichita@gmail.com

Acknowledgements: The authors thank the National Institute of Pneumology for providing the necessary data to conduct the study and also prioritizing the research in the field of TB treatment, and the secretariat of the European TB Research Initiative (ERI-TB) at the WHO Regional Office for Europe for organizing the Structured Operational Research Training (SORT-TB) for eastern European countries supported by the USAID-WHO regional partnership project to End TB in eastern Europe. SORT-TB curriculum was an adaptation of the UNICEF/UNDP/World Bank/WHO Special Programme for Research and Training in Tropical Diseases (TDR) SORT IT course (https://www.who.int/tdr/capacity/strengthening/sort/en/) to the eastern European context. We thank Yuliia Sereda for consultation on statistics and developing the figures.

Key words: Tuberculosis; drug-resistance; HADS; depression; anxiety.

Contributions: AS is the Principal Investigator of the study. AS, KA, AC, $\mathrm{AD}$, study concept and methodology; BM, leadership and support during the study implementation; BM, AS, coordination of the project during data collection; AS, KA, AD, ethics application development for the expedited review and approval by the Research Ethics Review Committee (WHO ERC); $\mathrm{ADu}$, data collection; KD, KA, data analysis; $\mathrm{AS}, \mathrm{KA}, \mathrm{AC}, \mathrm{AD}$, participation in manuscript preparation; AS, KA manuscript first draft; AC, CO, FP, RD AD, BM, substantial revisions to the initial version of the manuscript.

Funding: This study was funded by the United States Agency for International Development. The funding body had no role in study design, data collection and analysis, decision to publish, or preparation of the manuscript.

Conflict of interest: None to declare.

Ethics: Ethics approval was obtained from the Ethics Committee of National Institute of Pneumonology "Marius Nasta". In addition, the study protocol and informed consent form were approved by the World Health Organization Research Ethics Review Committee based in Geneva, Switzerland (ERC.0003320/16.04. 2020).

Received for publication: 10 July 2020

Accepted for publication: 29 October 2020.

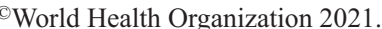

All rights reserved. The WHO Regional Office for Europe has granted the Publisher permission for the reproduction of this article.

Licensee PAGEPress, Italy

Monaldi Archives for Chest Disease 2021; 91:1704

doi: 10.4081/monaldi.2021.1704

Open access statement: In accordance with WHO's open-access publication policy for all work funded by WHO or authored/co-authored by WHO staff members, the WHO retains the copyright of this publication through a Creative Commons Attribution IGO licence (http://creativecommons.org/licenses/by/3.0/igo/legalcode) which permits unrestricted use, distribution and reproduction in any medium provided the original work is properly cited.

\section{Abstract}

Mental health comorbidities are common among tuberculosis patients, with higher prevalence among people with rifampicinresistant/multidrug-resistant (RR/MDR) tuberculosis. TB and depression share common risk factors adding to the overall disease burden. There is limited evidence about prevalence of depression and anxiety symptoms among tuberculosis patients in Romania. We assessed the prevalence of depression and anxiety symptoms and their evolution over the course of the treatment in $\mathrm{RR} / \mathrm{MDR}-\mathrm{TB}$ patients receiving in-patient care at the National Institute of Pneumonology (NIP) "Marius Nasta" in Romania during May-September 2020. We conducted a cohort study and used the Hospital Anxiety and Depression Scale (HADS) to assess the prevalence of depression and anxiety (defined as score $\geq 8$ ) symptoms at admission (baseline) and the second month of in-patient treatment (follow-up). Difference between baseline and follow-up depression and anxiety symptoms were assessed using McNemar test. Binary logistic regression was used to evaluate the association between sociodemographic and clinical characteristics with the presence of depression and anxiety symptoms at baseline. The cohort included 46 patients, $63 \%$ were male, mean age was 46 $( \pm 13.3)$ years. The prevalence of depression and anxiety in our cohort was $46 \%$ and $43 \%$ at baseline respectively, and $50 \%$ and $39 \%$, at the follow-up respectively. About one third (7/25) of patients who had normal HADS depression score at baseline, had an increase above the threshold at the second month of treatment. No statistical difference in prevalence of depression or anxiety was found between the baseline and second month of treatment. Unadjusted analysis showed that odds of depression at baseline was lower in patients with education above $8^{\text {th }}$ grade compared to patients with education below $8^{\text {th }}$ grade (odds ratio $=0.2,95 \%$ confidence interval: $0.1,0.8, \mathrm{p}=0.026$ ). The study revealed high prevalence of depression and anxiety among RR/MDR-TB patients admitted to the NIP, underlining the necessity of evaluating the mental health of TB patients and linking them to appropriate care. 


\section{Introduction}

Tuberculosis (TB) remains one of the major public health threats globally [1]. Around 10 million people fall ill with TB each year [1], of which about 3\% is estimated to occur in the World Health Organization (WHO) European Region [2]. Globally and regionally, TB incidence rate has been declining with the average annual rate of $1.6 \%$ and $5 \%$ respectively in the period $2000-2018$ [1]. This decline in the Region, however, is driven by drug-susceptible (DS) TB, whereas the rates of drug-resistance (DR) have been increasing [1,3]). WHO European Region accounts for $23 \%$ of all patients with rifampicin-resistant/multidrug-resistant tuberculosis (RR/MDR-TB) globally [2].

Romania is one of the 18 high-priority countries for TB control in the WHO European Region [2]. Although the TB incidence rate continues to decline on an annual average rate of $5.5 \%$, the country has the highest incidence rate of TB ( 68 per 100,000 population) [4] accounting for $23 \%$ of all TB patients in the European Union (EU) [2]. The RR/MDR-TB burden is one of the public health challenges in the country. In 2018, the estimated RR/MDR-TB incidence was 3.6 (range 2.9-4.5) per 100,000 population; however, of the expected 710 patients, only 470 were reported, meaning that the detection rate was only $66 \%[2,4]$. During the same year, the estimated proportion of RR/MDR-TB among new patients was $2.7 \%$ (range 2.3-3.2), among previously treated patients was $15 \%$ (range 13-16\%) [2,4]. The lower RR/MDR-TB detection rate may be due to the limited access to rapid-diagnostic test and to drugsusceptibility testing $[2,4,5]$ and could contribute to delayed diagnosis of RR/MDR-TB, as well as delayed initiation of treatment and respectively to poor treatment outcomes. The RR/MDR-TB treatment success rate for those who started treatment from 2015 to 2016 was around $50 \%$, which is lower than WHO target of $75 \%$ [2]. RR/MDR-TB treatment is complex, has a long duration and requires multiple drugs, including injectables [6,7].

Separately, depression and TB [8] are recognized as important public health concerns. WHO estimated that globally, the total number of people with depression exceeds 300 million and approximately the same number of people suffer from anxiety disorders [8]. Out of the estimated number of people with depression and anxiety in the world, $12 \%$ and $14 \%$ respectively are in WHO European Region [8]. In Romania, the estimated prevalence of depressive and anxiety disorders in general population was about $5 \%$ and $4 \%$, respectively [8].

Several studies have reported that mental health comorbidities are common in TB patients [9-12]. Previous studies from the WHO European Region, report a prevalence of depression and depressive symptoms among TB patients ranging from 19-65\% [13-17]. Among them two were conducted in Romania and the reported prevalence of depression among hospitalized TB patients was $38.9 \%$ [15] and $65 \%$ [17]. Results of a meta-analysis study showed that among TB patients the pooled estimated prevalence of depression is $45 \%$ [(18]. The prevalence of depression is higher among RR/MDR-TB patients [19]. Studies done outside of the WHO European Region reported that the prevalence of depression is higher than in the general population and ranging from $13 \%$ to $72 \%$ in pulmonary TB patients $[11,20-23]$ and from $23 \%$ to $70 \%$ in RR/MDR-TB patients [24].

A literature search reveals that mental disorders are associated with poor adherence to medication which could lead to irregular treatment especially in the treatment of illnesses with long duration [19].

Many people with depression are also exposed to TB risk factors including alcohol abuse, poverty, homelessness and congre- gate housing, thus they are at higher risk of developing the disease [25-27]. On the other hand, TB patients are at higher risk of developing depression due to several risk factors including drugs used for the treatment of RR/MDR-TB [27-30] poverty, social exclusion and drug abuse [27]. Thus, TB and depression act synergistically to worsen the overall disease burden. Hence, evaluating these comorbidities and linking them to appropriate care is crucial. There is limited evidence on this issue symptoms in Europe and in Romania [15,17]. In this study, we addressed this knowledge gap by assessing the prevalence of depression and anxiety symptoms and their change over the course of treatment among RR/MDR-TB patients receiving in-patient care in the National Institute of Pneumonology "Marius Nasta" in Romania during MaySeptember 2020. In addition, the study explored factors associated with depression and anxiety symptoms at the baseline.

\section{Materials and Methods}

\section{Study design and population}

We conducted a cohort study. The study enrolled all consecutive adult ( $\geq 18$ years old) RR/MDR-TB patients receiving inpatient care in the NIP in Romania during May-September 2020. Only patients who were able to speak Romanian and provided written informed consent were included into the study.

\section{Study setting}

In Romania, the Ministry of Health $(\mathrm{MoH})$ has the primary responsibility for TB control in the country and exercises power through the central unit of National Tuberculosis Programme (NTP) - the National Institute of Pneumonology "Marius Nasta" (NIP).

Integrated patient-centred care and prevention services are some of the key interventions in implementing NTP and include social and psychological support for TB patients. Since July 2014, some of the RR/MDR-TB patients have been benefitted from psychological counselling and social support in ambulatory care through internationally funded projects provided by NGOs. Moreover, psychological and social support is given to TB patients by four TB hospitals, including NIP since 2015. The services are free and are provided by psychologists and social workers.

\section{Study instrument}

We used the Hospital Anxiety and Depression Scale (HADS) to evaluate presence of depression and anxiety symptoms [31]. The questionnaire has been validated in many countries, languages and settings [32-34), and can be used free of charge. The instrument was not validated for Romanian population.

It consists of 14 questions, of which seven measure presence of depression symptoms and the remaining seven measure presence of anxiety symptoms. The evaluation of symptoms is done by scoring each response from 0 to 3 . A cumulative score is calculated after the interview, which is the sum of all responses. This is done separately for depression and anxiety. A score between 0-7 represents the absence of symptoms, a score between 8-10 represents a borderline case, whilst a score between 11-21 represents the presence of the symptoms. A review paper on the validity of the questionnaire showed that the optimal cut-off score for 'caseness' (the degree to which diagnostic criteria for depression and anxiety symptoms are applicable to a given patient) of depression and anxiety is 8 or above [32]. 


\section{Sources of data}

In the study are used two data sources: primary data obtained through the HADS questionnaire and secondary data acquired from the patients' medical records.

\section{Data collection and variables}

Each patient was assessed for presence of depression and anxiety symptoms at admission (baseline) and the second month of inpatient treatment (follow-up) using the HADS questionnaire. The questionnaire was self-administered. For those who were not able to complete the questionnaire on their own, it was administered by trained and experienced psychologist working at the facility.

Socio-demographic (age, sex, level of education, residence, marital status, employment, smoking status and alcohol consumption), and clinical characteristics (history of TB, laboratory assessment, chest X-Ray, comorbidities and clinical symptoms (defined as key symptoms if cough, fever and haemoptysis were present) were extracted from patients' charts and entered into the EpiData dataset by the study team. Data entry errors were identified and corrected through random checking of a sample of records.

\section{Analysis and statistics}

The study variables are summarized using frequencies for categorical variables and measures of central tendency for continuous variables.

Scoring of depression and anxiety symptoms was performed according to the HADS manual. We used a cut-off point of $8 / 21$ as a threshold for abnormal level of depression or anxiety symptoms. Prevalence of depression and anxiety was calculated for the whole sample and for each category in socio-demographic and clinical variables. Difference between the baseline and follow-up measurements was tested using McNemar test. Binary logistic regression was used to evaluate the association between sociodemographic and clinical characteristics and the presence of depression and anxiety symptoms at baseline. Respective crude odds ratios (OR) and
95\% confidence intervals (CI) were reported. The level of significance was set at $p<0.05$. The data analysis was conducted using SPSS (v.23, IBM, USA).

\section{Results}

The study cohort included 46 participants out of 76 eligible patients identified during the study period (Figure 1). Sociodemographic and clinical characteristics of the study population are presented in Table 1. Mean age of the study population was $46( \pm 13.3)$ years, majority of them were male $(29 / 46,63 \%)$ and $61 \%(28 / 46)$ were married or living with a partner. About $65 \%$ (30/46) of the study population had an education level above $8^{\text {th }}$ grade, and majority $54 \%(25 / 46)$ resided in rural areas. The majority of the participants $(38 / 46,83 \%)$ were current smokers and about one third of them reported high alcohol consumption $(35 \%$, $16 / 46)$. About half of the participants $(24 / 46,52 \%)$ were previously treated patients. X-ray assessment revealed cavities in about one third of the patients $(18 / 46,39 \%)$. Diabetes was diagnosed in four $(9 \%)$ and HIV infection in two (4\%) patients. Majority of the participants $(36 / 46,78 \%)$ had one or two key symptoms (cough, fever, haemoptysis) and about $15 \%$ (7/46) had all three symptoms. All patients had pulmonary TB.

The prevalence of depression and anxiety in our cohort at baseline were $46 \%(21 / 46)$ and $43 \%(20 / 46)$ respectively, and at follow-up were $50 \%(23 / 46)$ and $39 \%(18 / 46)$ respectively. At baseline $28 \%(13 / 46)$ and at follow-up 22\% (10/46) of the participants had both depression and anxiety. Seven study participants who had normal HADS score at baseline $(7 / 25,28 \%)$, developed depression at the follow-up, of which five moved to the borderline category and two to the abnormal category. Five study participants whose depression score was classified as abnormal (borderline and abnormal categories combined) at the baseline $(5 / 21,24 \%)$, showed normal scores at the follow-up. Detailed depiction of changes in the

RR/MDR- TB patients receiving in-patient care in the NIP during May - September $2020(\mathrm{~N}=76)$

\begin{tabular}{|l|}
\hline $\begin{array}{l}\text { Excluded: } \mathrm{n}=30(39 \%) \text {, of which } 25(33 \%) \\
\text { refused to participate, 5 (6\%) the questionnaire } \\
\text { was not possible to administer } \\
\text { baseline: } \mathrm{n}=46(60 \%)\end{array}$ \\
\hline $\begin{array}{l}\text { Screened for depression/anxiety at the } \\
\text { follow-up } \mathrm{n}=46(60 \%)\end{array}$ \\
\hline
\end{tabular}

Figure 1. Flow chart of the study participants: MDR-TB patients receiving in-patient care in the National institute of Pneumology "Marius Nasta" (NIP) in Romania (May-September 2020). 
Table 1. Baseline sociodemographic and clinical characteristics of patients with rifampicin-resistant/multidrug-resistant tuberculosis receiving in-patient care in the National Institute of Pneumonology (May-September) $(\mathrm{N}=46)$.

\begin{tabular}{|c|c|c|c|c|c|c|c|c|c|}
\hline \multicolumn{2}{|l|}{ Characteristics } & \multicolumn{4}{|c|}{ Depression symptoms at baseline } & \multicolumn{4}{|c|}{ Anxiety symptoms at baseline } \\
\hline Total & $\begin{array}{l}\text { Total } \\
\text { N (col\%) } \\
46(100)\end{array}$ & $\begin{array}{c}\text { HADS } \\
\text { score <8 } \\
\text { (Normal) } \\
\text { N (row } \%) \\
25(54)\end{array}$ & $\begin{array}{l}\text { HADS } \\
\text { score } \geq 8 \\
\text { (Abnormal) } \\
\text { N (row } \%) \\
21(46)\end{array}$ & p-value & $\begin{array}{l}\text { Crude OR } \\
(95 \% \text { CI) }\end{array}$ & $\begin{array}{c}\text { HADS } \\
\text { score }<8 \\
\text { (Normal) } \\
\text { N (row } \%) \\
26(57)\end{array}$ & $\begin{array}{l}\text { HADS } \\
\text { score } \geq 8 \\
\text { (Abnormal) } \\
N(\text { row } \%) \\
20(43)\end{array}$ & p-value & $\begin{array}{l}\text { Crude OR } \\
(95 \% \text { CI) }\end{array}$ \\
\hline \multicolumn{10}{|l|}{ Socio-demographic } \\
\hline $\begin{array}{c}\text { Age category } \\
\leq 30 \\
31-45 \\
46-60 \\
61+\end{array}$ & $\begin{array}{l}6(13) \\
11(24) \\
21(46) \\
8(17)\end{array}$ & $\begin{array}{l}3(50) \\
5(45) \\
14(67) \\
3(38)\end{array}$ & $\begin{array}{l}3(50) \\
6(55) \\
7(33) \\
5(63)\end{array}$ & $\begin{array}{l}0.460 \\
0.641 \\
1.000\end{array}$ & $\begin{array}{l}\text { ref. } \\
0.5(0.1-3.1) \\
1.7(0.2-14.3) \\
1(0-0)\end{array}$ & $\begin{array}{c}3(50) \\
5(45) \\
15(71) \\
3(38)\end{array}$ & $\begin{array}{l}3(50) \\
6(55) \\
6(29) \\
5(63)\end{array}$ & $\begin{array}{l}0.858 \\
0.334 \\
0.641\end{array}$ & $\begin{array}{c}\text { ref. } \\
1.2(0.2-8.8) \\
0.4(0.1-2.6) \\
1.7(0.2-14.3)\end{array}$ \\
\hline $\begin{array}{l}\text { Patient's sex } \\
\text { Male } \\
\text { Female } \\
\end{array}$ & $\begin{array}{l}29(63) \\
17(37)\end{array}$ & $\begin{array}{l}18(62) \\
7(41)\end{array}$ & $\begin{array}{l}11(38) \\
10(59)\end{array}$ & 0.174 & $\begin{array}{l}\quad \text { ref. } \\
2.3(0.7-7.9)\end{array}$ & $\begin{array}{l}18(62) \\
8(47)\end{array}$ & $\begin{array}{c}11(38) \\
9(53)\end{array}$ & 0.324 & $\begin{array}{l}\text { ref. } \\
1.8(0.5-6.2)\end{array}$ \\
\hline $\begin{array}{l}\text { Level of education } \\
\text { Below } 8^{\text {th }} \text { grade } \\
\text { Above } 8^{\text {th }} \text { grade }\end{array}$ & $\begin{array}{l}16(35) \\
30(65)\end{array}$ & $\begin{array}{c}5(31) \\
20(67)\end{array}$ & $\begin{array}{l}11(69) \\
10(33)\end{array}$ & 0.026 & $\begin{array}{c}\text { ref } \\
0.2(0.1-0.8)\end{array}$ & $\begin{array}{c}8(50) \\
18(60)\end{array}$ & $\begin{array}{c}8(50) \\
12(40)\end{array}$ & 0.516 & $\begin{array}{c}\text { ref } \\
0.7(0.2-2.3)\end{array}$ \\
\hline $\begin{array}{l}\text { Place of current residence } \\
\text { Urban } \\
\text { Rural }\end{array}$ & $\begin{array}{l}21(46) \\
25(54)\end{array}$ & $\begin{array}{l}13(62) \\
12(48)\end{array}$ & $\begin{array}{c}8(38) \\
13(52)\end{array}$ & 0.347 & $\begin{array}{c}\text { ref } \\
1.8(0.5-5.7)\end{array}$ & $\begin{array}{l}13(62) \\
13(52)\end{array}$ & $\begin{array}{c}8(38) \\
12(48)\end{array}$ & 0.500 & $\stackrel{\text { ref }}{1.5(0.5-4.9)}$ \\
\hline $\begin{array}{l}\text { Marital status } \\
\text { Single } \\
\text { Married/Co-habitation }\end{array}$ & $\begin{array}{l}18(39) \\
28(61)\end{array}$ & $\begin{array}{l}10(56) \\
15(54)\end{array}$ & $\begin{array}{l}8(44) \\
13(46)\end{array}$ & 0.895 & $\begin{array}{c}\text { ref } \\
1.1(0.3-3.6)\end{array}$ & $\begin{array}{l}10(56) \\
16(57)\end{array}$ & $\begin{array}{l}8(44) \\
12(43)\end{array}$ & 0.916 & $\begin{array}{c}\text { ref } \\
0.9(0.3-3.1)\end{array}$ \\
\hline $\begin{array}{l}\text { Employment status } \\
\text { Employed } \\
\text { Unemployed } \\
\end{array}$ & $\begin{array}{l}27(59) \\
19(41)\end{array}$ & $\begin{array}{l}17(63) \\
8(42)\end{array}$ & $\begin{array}{l}10(37) \\
11(58)\end{array}$ & 0.165 & $\begin{array}{c}\text { ref } \\
2.3(0.7-7.8)\end{array}$ & $\begin{array}{l}18(67) \\
8(42)\end{array}$ & $\begin{array}{c}9(33) \\
11(58)\end{array}$ & 0.102 & $\begin{array}{c}\text { ref } \\
2.7(0.8-9.2)\end{array}$ \\
\hline $\begin{array}{l}\text { Current smoking status } \\
\text { Non-smoker } \\
\text { Smoker }\end{array}$ & $\begin{array}{c}8(17) \\
38(83)\end{array}$ & $\begin{array}{c}4(50) \\
21(55)\end{array}$ & $\begin{array}{c}4(50) \\
17(45)\end{array}$ & 0.786 & $\begin{array}{c}\text { ref } \\
0.8(0.2-3.7)\end{array}$ & $\begin{array}{c}5(63) \\
21(55)\end{array}$ & $\begin{array}{c}3(38) \\
17(45)\end{array}$ & 0.708 & $\begin{array}{c}\text { ref } \\
1.3(0.3-6.5)\end{array}$ \\
\hline $\begin{array}{l}\text { Level of alcohol consumption } \\
\text { Low or no } \\
\text { High }\end{array}$ & $\begin{array}{l}30(65) \\
16(35)\end{array}$ & $\begin{array}{l}15(50) \\
10(63)\end{array}$ & $\begin{array}{l}15(50) \\
6(38)\end{array}$ & 0.419 & $\begin{array}{c}\text { ref } \\
0.6(0.2-2.1)\end{array}$ & $\begin{array}{l}14(47) \\
12(75)\end{array}$ & $\begin{array}{c}16(53) \\
4(25)\end{array}$ & 0.071 & $\begin{array}{c}\text { ref } \\
0.3(0.1-1.1)\end{array}$ \\
\hline \multicolumn{10}{|l|}{ Clinical } \\
\hline $\begin{array}{l}\text { Type of TB case } \\
\text { New } \\
\text { Retreatment }\end{array}$ & $\begin{array}{l}22(48) \\
24(52)\end{array}$ & $\begin{array}{l}12(55) \\
13(54)\end{array}$ & $\begin{array}{l}10(45) \\
11(46)\end{array}$ & 0.979 & 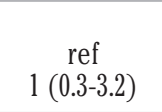 & $\begin{array}{l}14(64) \\
12(50)\end{array}$ & $\begin{array}{l}8(36) \\
12(50)\end{array}$ & 0.353 & $\underset{\text { ref }}{1.7(0.5-5.7)}$ \\
\hline $\begin{array}{l}\text { Baseline smear microscopy } \\
\text { Positive } \\
\text { Negative } \\
\text { Not done } \\
\end{array}$ & $\begin{array}{l}30(65) \\
15(33) \\
1(2)\end{array}$ & $\begin{array}{l}16(53) \\
8(53) \\
1(100)\end{array}$ & $\begin{array}{l}14(47) \\
7(47) \\
0(0)\end{array}$ & $\begin{array}{l}1.000 \\
1.000\end{array}$ & $\begin{array}{c}\text { ref } \\
1(0.3-3.5) \\
0(0-0)\end{array}$ & $\begin{array}{l}17(57) \\
8(53) \\
1(100)\end{array}$ & $\begin{array}{l}13(43) \\
7(47) \\
0(0)\end{array}$ & $\begin{array}{l}0.832 \\
1.000\end{array}$ & $\begin{array}{c}\text { ref } \\
1.1(0.3-4) \\
0(0-0)\end{array}$ \\
\hline $\begin{array}{l}\text { Baseline culture } \\
\text { Positive } \\
\text { Negative } \\
\text { Not done }\end{array}$ & $\begin{array}{l}31(67) \\
14(30) \\
1(2)\end{array}$ & $\begin{array}{l}17(55) \\
7(50) \\
1(100)\end{array}$ & $\begin{array}{l}14(45) \\
7(50) \\
0(0)\end{array}$ & $\begin{array}{l}0.763 \\
1.000\end{array}$ & $\begin{array}{c}\text { ref } \\
1.2(0.3-4.3) \\
0(0-0)\end{array}$ & $\begin{array}{l}17(55) \\
8(57) \\
1(100)\end{array}$ & $\begin{array}{l}14(45) \\
6(43) \\
0(0)\end{array}$ & $\begin{array}{l}0.886 \\
1.000\end{array}$ & $\begin{array}{l}\text { ref } \\
0.9(0.3-3.3) \\
0(0-0)\end{array}$ \\
\hline $\begin{array}{l}\text { Resistance category } \\
\text { Rifampicin resistance } \\
\text { Rifampicin and isoniazid resistance } \\
\text { Resistance to FLD }\end{array}$ & $\begin{array}{l}16(36) \\
20(44) \\
9(20)\end{array}$ & $\begin{array}{l}7(44) \\
11(55) \\
6(67)\end{array}$ & $\begin{array}{l}9(56) \\
9(45) \\
3(33)\end{array}$ & $\begin{array}{l}0.503 \\
0.277\end{array}$ & $\begin{array}{c}\text { ref } \\
0.6(0.2-2.4) \\
0.4(0.1-2.1)\end{array}$ & $\begin{array}{l}7(44) \\
11(55) \\
7(78)\end{array}$ & $\begin{array}{l}9(56) \\
9(45) \\
2(22)\end{array}$ & $\begin{array}{l}0.503 \\
0.112\end{array}$ & $\begin{array}{c}\text { ref } \\
0.6(0.2-2.4) \\
0.2(0-1.4)\end{array}$ \\
\hline $\begin{array}{l}\text { RX pulmonary cavities } \\
\text { No } \\
\text { Yes }\end{array}$ & $\begin{array}{l}28(61) \\
18(39)\end{array}$ & $\begin{array}{l}13(46) \\
12(67)\end{array}$ & $\begin{array}{l}15(54) \\
6(33)\end{array}$ & 0.183 & $\begin{array}{c}\text { ref } \\
0.4(0.1-1.5)\end{array}$ & $\begin{array}{l}16(57) \\
10(56)\end{array}$ & $\begin{array}{l}12(43) \\
8(44)\end{array}$ & 0.916 & $\begin{array}{c}\text { ref } \\
1.1(0.3-3.5)\end{array}$ \\
\hline $\begin{array}{l}\text { Adverse reaction }^{\circ} \\
\text { No } \\
\text { Yes }\end{array}$ & $\begin{array}{l}29(63) \\
17(37)\end{array}$ & $\begin{array}{l}16(55) \\
9(53)\end{array}$ & $\begin{array}{l}13(45) \\
8(47)\end{array}$ & 0.883 & $\begin{array}{c}\text { ref } \\
1.1(0.3-3.6)\end{array}$ & $\begin{array}{l}15(52) \\
11(65)\end{array}$ & $\begin{array}{c}14(48) \\
6(35)\end{array}$ & 0.393 & $\begin{array}{c}\text { ref } \\
0.6(0.2-2)\end{array}$ \\
\hline $\begin{array}{l}\text { Having diabetes } \\
\text { No } \\
\text { Yes }\end{array}$ & $\begin{array}{c}42(91) \\
4(9)\end{array}$ & $\begin{array}{l}21(50) \\
4(100)\end{array}$ & $\begin{array}{c}21(50) \\
0(0)\end{array}$ & 0.999 & $\begin{aligned} & \text { ref } \\
0 & (0-0)\end{aligned}$ & $\begin{array}{l}24(57) \\
2(50)\end{array}$ & $\begin{array}{l}18(43) \\
2(50)\end{array}$ & 0.784 & $\underset{\text { ref }}{1.3(0.2-10.4)}$ \\
\hline $\begin{array}{l}\text { Associated HIV infection } \\
\text { No } \\
\text { Yes }\end{array}$ & $\begin{array}{c}44(96) \\
2(4)\end{array}$ & $\begin{array}{l}23(52) \\
2(100)\end{array}$ & $\begin{array}{c}21(48) \\
0(0)\end{array}$ & 0.999 & $\begin{array}{c}\text { ref } \\
0(0-0)\end{array}$ & $\begin{array}{c}25(57) \\
1(50)\end{array}$ & $\begin{array}{c}19(43) \\
1(50)\end{array}$ & 0.850 & $\begin{array}{c}\text { ref } \\
1.3(0.1-22.4)\end{array}$ \\
\hline $\begin{array}{l}\text { Presence of key symptoms (cough, fever } \\
\text { None } \\
\text { At least one } \\
\text { All }\end{array}$ & $\begin{array}{l}\text { emoptysis) } \\
3(7) \\
36(78) \\
7(15)\end{array}$ & $\begin{array}{l}1(33) \\
21(58) \\
3(43)\end{array}$ & $\begin{array}{l}2(67) \\
15(42) \\
4(57)\end{array}$ & $\begin{array}{l}0.418 \\
0.779 \\
\end{array}$ & $\begin{array}{c}\text { ref } \\
0.4(0-4.3) \\
0.7(0-11.3)\end{array}$ & $\begin{array}{l}2(67) \\
20(56) \\
4(57)\end{array}$ & $\begin{array}{l}1(33) \\
16(44) \\
3(43)\end{array}$ & $\begin{array}{c}3(7) \\
36(78) \\
7(15)\end{array}$ & $\begin{array}{c}1(33) \\
21(58) \\
3(43)\end{array}$ \\
\hline
\end{tabular}

HIV, human immunodeficiency virus; RX, X-ray; TB, tuberculosis; FLD, first line drugs; OR, odds ratio; CI, confidence interval; ${ }^{\circ}$ adverse events during the first two months of TB treatment. 
depression scores are presented in Figure 2. Four participants who at baseline had normal HADS score for anxiety (4/26, 15\%), developed anxiety at the follow-up, specifically three of them had borderline HADS score and one abnormal HADS score.

No statistical difference was found between the depression and anxiety symptoms at baseline and at the second month of the treatment (Figures 2 and 3). Unadjusted analysis revealed that odds of depression decreased in patients with higher education $\left(8^{\text {th }}\right.$ grade and above) compared to lower education (below $8^{\text {th }}$ grade) (odds ratio $=0.2,95 \%$ confidence interval: $0.1,0.8, \mathrm{p}=0.026$ ) (Table 1$)$.

\section{Discussion}

We describe the prevalence of depression symptoms as high as $46 \%$ among RR/MDR TB patients at admission. The prevalence estimate is comparable to other studies. In a meta-analysis of 4,903 patients with TB from seven countries, pooled estimated prevalence of depression was $45 \%$ (95\% CI 38.04-52.55), with higher prevalence among MDR-TB 52.34\% (95\% CI 38.09-66.22) patients [18]. Other observational studies report the prevalence of depression and depressive symptoms ranging from 19-65\% [1317]. Among them two studies conducted in Romania with the reported prevalence of depression 38.9\% [15] and 65\% [17]. These studies were conducted in a single site and include-susceptible TB patients only. One of these studies reported no statistical difference between depression at baseline and at 6 weeks of hospital treatment among 63 DS TB patients [17]. This is in line with our findings, though both studies had small sample sizes and were not powered adequately to detect statistical differences. In contrast, a study conducted in Armenia found that at baseline the prevalence of depression among 395 DS TB patients was $22 \%$, which decreased significantly to $11 \%$ at the end of the TB treatment course.

The prevalence of depression among TB patients is reported to be higher compared to the general population. Our findings confirm this, as the prevalence of depressive and anxiety disorders in general population in Romania was much lower at 5\% and $4 \%$, respectively [8]. A study from Romania with head-to-head comparison shows that the prevalence of depression is significantly higher among patients compared to the healthy individuals without TB $(65 \%$ vs $11 \%, \mathrm{p}<0.05)$.

We have identified seven studies that estimated the prevalence of depression and anxiety symptoms among TB patients using HADS questionnaire. Of them, only one was comparable to our study in terms of drug resistance profile, enrolment of hospitalized study population and usage of cut of point $8+$ for categorization of caseness (the degree to which diagnostic criteria for depression and anxiety symptoms are applicable to a given patient) of depression and anxiety. The study was conducted in India and reported prevalence of depression was $55 \%$ and $56 \%$ for anxiety [35]. Prevalence of anxiety symptoms in our study was lower (43\%).

Another study assessing the prevalence of depression among TB patients using HADS questionnaire was conducted in China among 1,252 DS TB patients receiving directly observed treatment [36]. The study reported a prevalence of $18 \%$ depression and $19 \%$ anxiety. In addition, the study identified independent risk factors associated with depression, including dyspnoea, tracheobronchial $\mathrm{TB}$, lower education and low income [36]. Unadjusted analysis in our study also found association between the lower education and higher odds of depression.

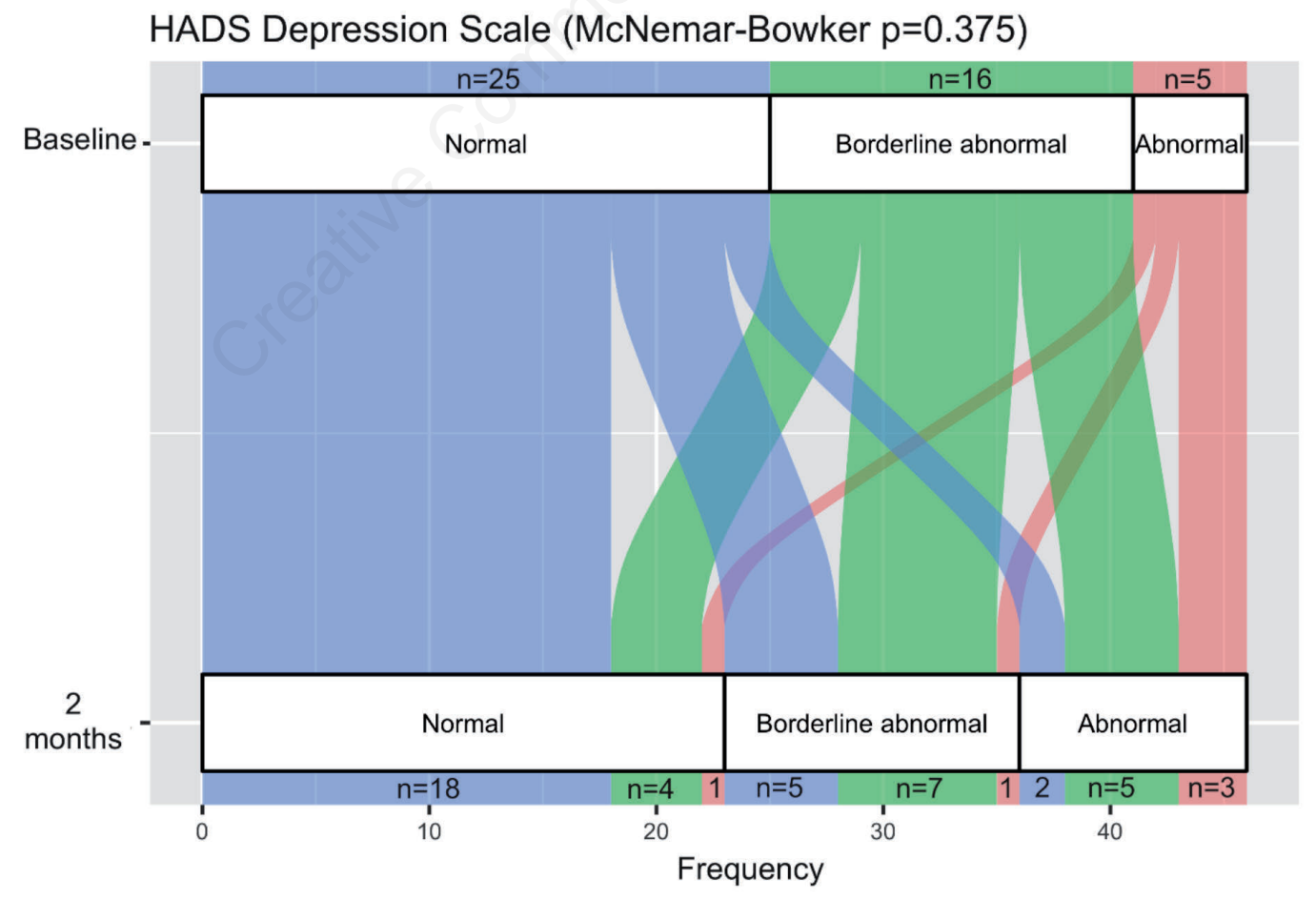

Figure 2. Comparison of depression symptoms at admission (baseline) and the second month of in-patient treatment (follow-up) among rifampicin-resistant/multidrug-resistant tuberculosis receiving in-patient care in the National Institute of Pneumonology (MaySeptember 2020). 
We report for the first time the prevalence of depression and anxiety symptoms among RR/MDR-TB patients in Romania. An independent, trained psychologist enrolled the study participants and facilitated the data collection. the physicians or healthcare workers who were involved in delivery of care were not involved in recruitment or administration of the questionnaire. This helped in minimizing the desirability bias and patients felt free in their responses.

The HADS questionnaire has been validated in other settings and widely used globally. A systematic review study of validation works for HADS questionnaire showed that with cut of point $\geq 8$, HADS questionnaire assures optimal sensitivity and specificity. However, there is also a growing criticism of latent structure of HADS questionnaire in the literature [37]. In clinical practice the HADS questionnaire is a convenient tool for the assessment of depression and anxiety symptoms and their evolution. It has been recommended by the National Institute for Health and Care Excellence (NICE) in UK as one of the tools for assessing the psychological conditions [38]. However, depression and anxiety symptoms cannot be attributed to a depression as a psychiatric diagnosis.

The study had several limitations. First, the small sample size, did not provide sufficient power to detect any adjusted associations between depression or anxiety and other clinical and socio-demographic variables. For the same reason, the study was underpowered to detect changes in depression levels during the course of treatment. Second, the study was conducted in a single site, which limits generalizability of findings. However, the NIP is a central and the largest hospital for the treatment of the RR/MDR-TB patients in Romania, accounting for $59 \%$ of all RR/MDR-TB cases. Third, we had a high non-response rate. We do not know if non-responders were similar to responders and hence the effect of non-response on prevalence estimates cannot be ruled out. Fourth, behavioural characteristics, including smoking and alcohol abuse were self-reported, which could influence the data quality. Finally, we were not able to obtain information on important clinical covariates, such as co-infection with $\mathrm{HCV}$.

The study revealed high prevalence of depression and anxiety among RR/MDR-TB patients admitted to The National Institute of Pneumology "Marius Nasta". This calls routine assessment of all TB patients for depression and anxiety and linking them to appropriate care. This is likely to improve the overall quality of life for TB patients, complementing the evaluation and potential rehabilitation of post-TB treatment sequelae as recently discussed within the scientific community $[37,39]$.

Future research on depression and anxiety with higher sample size is recommended to estimate independent risk factors for depression and anxiety, as well as factors associated with the change in the depression and anxiety score during the course of long treatment duration.

\section{References}

1. WHO. Global tuberculosis report 2019. Geneva: World Health Organization; 2019. Available from: http://www.who.int/tb/publications/global_report/en/

2. WHO. Tuberculosis surveillance and monitoring in Europe 2019: 2017 data. Accessed on: 2019 Nov 22. Available from: https://apps.who.int/iris/handle/10665/311349

3. Dadu A, Hovhannesyan A, Ahmedov S, et al. Drug-resistant tuberculosis in eastern Europe and central Asia: a time-series

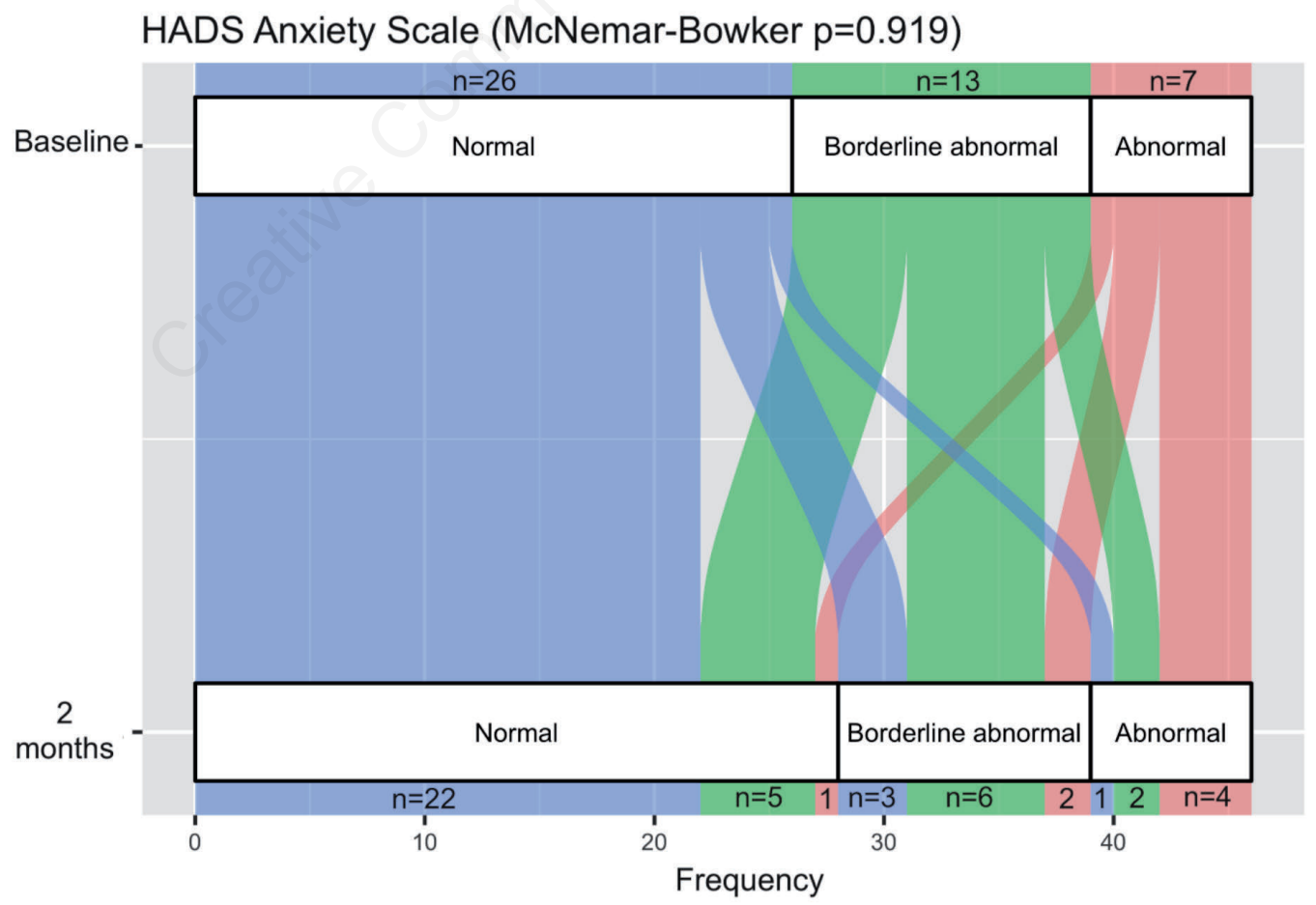

Figure 3. Comparison of anxiety symptoms at admission (baseline) and the second month of in-patient treatment (follow-up) among rifampicin-resistant/multidrug-resistant tuberculosis patients receiving in-patient care in the National Institute of Pneumonology (May-September 2020). 
analysis of routine surveillance data. Lancet Infect Dis 2020;20:250-8.

4. WHO. Romania Tuberculosis Profile. 2018 Accessed on: 2019 Nov 21. Available from: https:/www.who.int/data/gho/data/ countries/country-details/GHO/romania?countryProfileId= d97baa4c-59b0-44e3-998b-c82831e04ea6

5. Romania's Ministry of Health. National Strategy of TB control in Romania 2015-2020.

6. Migliori GB, Tiberi S, Zumla A, et al. MDR/XDR-TB management of patients and contacts: Challenges facing the new decade. The 2020 clinical update by the Global Tuberculosis Network. Int J Infect Dis 2020;92:S15-25.

7. WHO. Use of high burden country lists for TB by WHO in the post-2015 era meeting of WHO's Strategic and Technical Advisory Group for TB (STAG-TB). 2015. Available from: https://www.who.int/tb/publications/global_report/high_tb_burdencountrylists2016-2020.pdf

8. WHO. Depression and other common mental disorders. Global health estimates. 2017. Available from: https:/www.who.int/ mental_health/management/depression/prevalence_global_heal th_estimates/en/

9. Ige OM, Lasebikan VO. Prevalence of depression in tuberculosis patients in comparison with non-tuberculosis family contacts visiting the DOTS clinic in a Nigerian tertiary care hospital and its correlation with disease pattern. Ment Health Fam Med 2011;8:235-41.

10. Peltzer K, Naidoo P, Matseke G, et al. Prevalence of psychological distress and associated factors in tuberculosis patients in public primary care clinics in South Africa. BMC Psychiatry 2012;12:89.

11. Husain MO, Dearman SP, Chaudhry IB, et al. The relationship between anxiety, depression and illness perception in tuberculosis patients in Pakistan. Clin Pract Epidemiol Ment Health 2008;4:4.

12. Duko B, Gebeyehu A, Ayano G. Prevalence and correlates of depression and anxiety among patients with tuberculosis at WolaitaSodo University Hospital and Sodo Health Center, WolaitaSodo, South Ethiopia, Cross sectional study. BMC Psychiatry 2015;15:214.

13. Truzyan N, Petrosyan V, Harutyunyan A, et al. Depressive symptoms among TB patients in Armenia. Eur J Public Health 2015;25:ckv176.166.

14. Moussas G, Tselebis A, Karkanias A, et al. A comparative study of anxiety and depression in patients with bronchial asthma, chronic obstructive pulmonary disease and tuberculosis in a general hospital of chest diseases. Ann Gen Psychiatry 2008;7:7.

15. Man MA, Bondor C, Dantes E, et al. Depressive syndrome, anxiety and illness perception in tuberculosis patients. Available from: http://www.wseas.us/e-library/conferences/2011/ Cambridge/MEDICAL/MEDICAL-28.pdf

16. Aydin IO, Uluşahin A. Depression, anxiety comorbidity, and disability in tuberculosis and chronic obstructive pulmonary disease patients: applicability of GHQ-12. Gen Hosp Psychiatry 2001;23:77-83.

17. Iovan I, Vancea D, Fratila Z, Burlacu O. Anxiety and depression in tuberculosis hospitalized patients in comparison to healthy individuals. Eur Respir J 2012;40:P2591.

18. Duko B, Bedaso A, Ayano G. The prevalence of depression among patients with tuberculosis: A systematic review and meta-analysis. Ann Gen Psychiatry 2020;19:30.

19. Sweetland AC, Kritski A, Oquendo MA, et al. Addressing the tuberculosis-depression syndemic to end the tuberculosis epidemic. Int J Tuberc Lung Dis 2017;21:852-61.
20. Shen TC, Wang CY, Lin CL, et al. People with tuberculosis are associated with a subsequent risk of depression. Eur J Intern Med 2014;25:936-40.

21. Natani GD, Jain NK, Sharma TN, et al. Depression in TB patients: correlation with duration of disease and response to anti-tuberculous chemotherapy. Indian J Tubercul 1985;32:195.

22. Balaji AL, Abhishekh HA, Kumar NC, Mehta RM. Depression in patients with pulmonary tuberculosis in a tertiary care general hospital. Asian J Psychiatry 2013;6:251-2.

23. Aamir S, Aisha. Co-morbid anxiety and depression among pulmonary tuberculosis patients. J Coll Physicians Surg Pakistan 2010;20:703-4.

24. Thomas BE, Shanmugam P, Malaisamy M, et al. Psycho-socioeconomic issues challenging multidrug resistant tuberculosis patients: A systematic review. PloS One 2016;11:e0147397.

25. McQuistion HL, Colson P, Yankowitz R, Susser E. Tuberculosis infection among people with severe mental illness. Psychiatr Serv 1997;48:833-5.

26. Lopez AG. Tuberculosis and the severely mentally ill. Am J Psychiatry 1994;151:151-2.

27. Chandra M, Rana P, Chandra K, Arora VK. Tuberculosis Depression syndemic: A public health challenge. Indian J Tuberc 2019;66:197-202.

28. Bakhla A, Gore P, Srivastava S. Cycloserine induced mania. Indian Psychiatry J 2013;22:69.

29. Saraf G, Akshata JS, Kuruthukulangara S, et al. Cycloserine induced delirium during treatment of multi-drug resistant tuberculosis (MDR-TB). Egypt J Chest Dis Tuberc 2015;64:449-51.

30. Das D, Singh H. Cycloserine induced depression in a case of multidrug resistant tuberculosis. World J Pharm Phamaceutical Sci 2017;6:1069-73.

Snaith RP, Zigmond AS. The hospital anxiety and depression scale. Acta Psychiatr Scand 1983;67:361-70.

32. Bjelland I, Dahl AA, Haug TT, Neckelmann D. The validity of the Hospital Anxiety and Depression Scale: An updated literature review. J Psychosom Res 2002;52:69-77.

33. Herrmann C. International experiences with the hospital anxiety and depression scale - A review of validation data and clinical results. J Psychosom Res 1997;42:17-41.

34. Snaith RP. The hospital anxiety and depression scale. Health Qual Life Outcomes 2003;1:29.

35. Chandra N, Sheth S, Mehta R. Socio-demographic, psychosocial factors in MDR and XDR-Tb with psychiatric co morbidities and their relation with drug adherence. IOSR J Dent Med Sci 2017;16:5-8.

36. Wang XB, Li XL, Zhang Q, et al. A survey of anxiety and depressive symptoms in pulmonary tuberculosis patients with and without tracheobronchial tuberculosis. Front Psychiatry 2018;9:308.

37. Visca D, Tiberi S, Pontali E, et al. Tuberculosis in the time of COVID-19: quality of life and digital innovation. Eur Respir J 2020;56:2001998.

38. National Institute for Health and Care Excellence (NICE) [Internet]. Common mental health problems: identification and pathways to care. Clinical guideline. 2011. Accessed on: 2019 Nov 22. Available from: https://www.nice.org.uk/guidance/ $\operatorname{cg} 123$

39. Visca D, Zampogna E, Sotgiu G, et al. Pulmonary rehabilitation is effective in patients with tuberculosis pulmonary sequelae. Eur Respir J 2019;53:1802184. 